\title{
EXPRESSION OF INTERLEUKIN-10 AND ITS VALUE AS A POTENTIAL MARKER IN ORAL SQUAMOUS CELL CARCINOMA
}

\author{
Maggi N. Ali ${ }^{1} B D S$, Taissir A. Omar ${ }^{2} P h D$, Sahar M. El Sheikh ${ }^{3} P h D$, Gamal A. Swaify ${ }^{4} P h D$, \\ Amira I. Fayad ${ }^{5} P h D$
}

\begin{abstract} role in cancer pathogenesis. It contributes to tumor growth and in other cases to tumor rejection. levels. with a human IL-10 ELISA Kit in both patients and controls. tissue expression and its serum and salivary levels in OSCC patients. other. This could reflect the same way of regulation of IL-10 in different parts of the body.

KEYWORDS: OSCC, Cytokines, IL-10, Imunohistochemistry, ELISA.

1- Instructor in Oral Pathology Department, Faculty of Dentistry, Alexandria University.

2- Professor in Oral Pathology Department.

3- Vice Dean of student`s affairs, Professor in Oral Pathology Department.

4- Professor in Cranio Maxillofacial and Plastic Surgery.

5- Lecturer in Clinical Pathology Department, Faculty of Medicine.
\end{abstract}

INTRODUCTION: Oral squamous cell carcinoma (OSCC) is the commonest malignancy in oral cavity. Dysregulated inflammatory processes could impose a cancer risk. Cytokines are inflammatory mediators that can induce cell proliferation. Interleukin-10 is a pleiotropic cytokine which has a dual

OBJECTIVES: To evaluate and correlate the expression of IL-10 in different histopathological grades of OSCC, as well as to assess its serum and salivary

MATERIALS AND METHODS: Immunohistochemical (IHC) study using the IL-10 antibody was done on 20 surgical specimens and 5 normal mucosal tissues taken from OSCC patients and healthy individuals, respectively. Serum and salivary levels of IL-10 were also measured

RESULTS: OSCC biopsies showed immunoreactivity to IL-10, while normal tissues were immunonegative. The IHC staining intensity was directly proportional to the grading of OSCC. Conversely, it showed no significant correlation to the disease stage. The difference in the serum and salivary IL-10 levels in patients and controls was not statistically significant. However, there was a significant correlation between IL-10

CONCLUSIONS: IL-10 is expressed in OSCC biopsies. Additionally, the levels of IL-10 in tissue, serum and saliva were correlated to each

\section{INTRODUCTION}

Oral cancer is a global health problem. Around 300,000 patients are annually estimated to have this disease worldwide. Our main interest falls in head and neck squamous cell carcinoma (HNSCC) in general and oral squamous cell carcinoma (OSCC ) in specific because of its alarming incidence and mortality (1).

Oral squamous cell carcinoma is a multifactorial disease. It is influenced by genetic modifications; as well as numerous environmental factors, such as smoking, tobacco chewing, alcohol consumption, infection by oncogenic viruses, and low intake of fruits and vegetables $(2,3)$.

During the last decade, a clear evidence has been obtained that inflammation plays a critical role in tumorigenesis (4). Cytokines are important components of inflammation. They are cell-signaling protein molecules which affect the intercellular communication (5). They are observed to be produced in the tumor microenvironment, indicating their suggestive role in cancer pathogenesis (6).

Interleukin-10 is a potent pleiotropic cytokine with immunosuppressive and anti-inflammatory functions, as well as anti-cancer activities (2). Various cell populations are able to produce it. However, the major source of IL-10 production is macrophages (7). Increased IL-10 expression in tumor tissues, serum and saliva was noted in different cancer types (8-10). In addition, this raised concentration was proposed as an indicator of poor prognosis (11).

The aim of the present work was to evaluate the expression of IL-10 in different grades of OSCC, and to correlate this expression to the disease stage. The assessment of IL-10 serum and salivary concentrations using ELISA analysis was also aimed. Finally, correlating the tissue, serum and salivary concentrations of IL-10 was done.

\section{MATERIALS AND METHODS}

The study was performed in the Faculty of Dentistry, Alexandria University after gaining the approval of the Research Ethics Committee. Twenty OSCC patients collected from the CranioMaxillofacial and Plastic Surgery Department were included. As well as, five age and gender matched non-cancer patients who were indicated for alveoloplasty selected from the Oral and Maxillofacial Surgery Department serving as negative control. All patients signed informed consents for the agreement to participate in the study. Patients and controls who presented with signs of active infection, autoimmune diseases, or having a history of radiotherapy, chemotherapy or other cancers were excluded from the study.

All the study participants were instructed to refrain from eating, drinking, smoking, or carrying out oral hygiene procedures for at least one hour before sample collection. Three $\mathrm{ml}$ of blood and 1$2 \mathrm{ml}$ of saliva samples were taken from the patients and controls before surgery. Blood samples were allowed to clot for at least 30 minutes, and then centrifuged for 10 minutes at $1300 \mathrm{rpm}$. The serum layer was removed and stored at $-20^{\circ} \mathrm{C}$. Saliva samples were also centrifuged and frozen until analysis. Serum and salivary levels of IL-10 were measured using a human IL-10 
ELISA Kit (BioLegend, San Diego, USA) according to the manufacturer`s instructions.

Biopsies were taken from the tumor tissues in cancer patients as well as from the discarded mucosal tissues during alveoloplasty in non-cancer patients. The specimens were fixed in $10 \%$ neutral buffered formalin, processed and embedded in paraffin wax using the conventional procedures. Serial sections of 3-4 $\mu \mathrm{m}$ thickness were placed on glass slides and stained using Hematoxylin and Eosin (H\&E). Immunohistochemical (IHC) staining using the IL-10 antibody (US Biological, USA) was also performed using the Labeled Strept- Avidin Biotin complex method (LSAB) (15). Then, the sections were examined by the image analyzer computer system using the software Leica Qwin 500 (Leica Microsystems Inc., Heerbrugg, Switzerland).

\section{STATISTICAL ANALYSIS}

The difference in the mean area percent and mean optical density of IL-10 in OSCC samples in the different grades were estimated using the one-way analysis of ANOVA.

The difference in the concentration of serum and salivary human IL-10 was estimated in the cancer and non-cancer groups using student $(\mathrm{t})$ test.

A (P) value less than 0.05 was considered significant. The values were given as a mean value \pm SD (standard deviation).

\section{RESULTS}

\section{Clinical Results}

The demographic data of the patients included in the study are shown in Table 1. The age of the patients included in this study ranged between 35 and 76 years. Thirteen patients (65\%) were males and seven patients (35\%) were females.

The most common site of occurrence of OSCC was the lateral side of the tongue (35\%), followed by the buccal mucosa (25\%), then floor of the mouth (15\%). Finally, both the alveolar mucosa and the maxillary tuberosity were equal (10\% for each), and the lower lip was the least occurring site (5\%).

The clinical staging of the patients was as follows; stage II was the predominant (40\%), followed by stage I (35\%), then stage IVA (20\%), and the least common stage was stage III (5\%).

Table 1: Distribution of the Studied OSCC Cases according to Demographic Data.

\begin{tabular}{|c|c|c|}
\hline$x_{-2}$ & $(n=20)$ & $\%$ \\
\hline \multicolumn{3}{|l|}{ Age } \\
\hline$\leq 60$ & 6 & 30 \\
\hline$>60$ & 14 & 70 \\
\hline Min. - Max. & \multicolumn{2}{|c|}{$35-76$} \\
\hline Mean \pm SD. & \multicolumn{2}{|c|}{$60 \pm 9.5$} \\
\hline Median & \multicolumn{2}{|c|}{63} \\
\hline Gender & & \\
\hline Male & 13 & 65 \\
\hline Female & 7 & 35 \\
\hline $\begin{array}{l}\text { Clinical Variants } \\
\text { Ulcerative } \\
\text { Exophytic } \\
\text { Leukoplakic }\end{array}$ & $\begin{array}{r}12 \\
6 \\
2\end{array}$ & $\begin{array}{l}60 \\
30 \\
10\end{array}$ \\
\hline $\begin{array}{c}\text { Lymph node } \\
\text { metastasis } \\
\text { Positive } \\
\text { Negative }\end{array}$ & $\begin{array}{l}4 \\
16\end{array}$ & $\begin{array}{l}20 \\
80\end{array}$ \\
\hline
\end{tabular}

\section{Histopathological Results}

The microscopical examination revealed that $35 \%$ of the cases were well differentiated, $55 \%$ were moderately differentiated and $10 \%$ were poorly differentiated.

\section{Immunohistochemical Results}

All cases of normal oral mucosa $(n=5)$ showed negative immunoreactivity for IL-10 (Figure 1), while OSCC biopsies $(n=20)$ were immunostained. Cytoplasmic IL-10 immunosignaling was detected in the well and moderately differentiated grades of OSCC, while both cytoplasmic and nuclear immunoreactions were observed in the poorly differentiate type (Figures 2, 3, 4, 5, and 6).

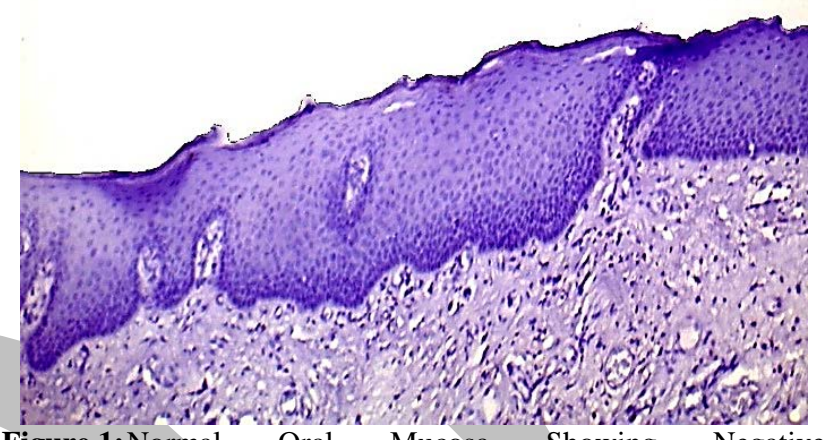

Figure 1: Normal Oral Mucosa Showing Negative Immunoreactivity for IL-10 (Immuno stain of IL-10x100).

The IHC staining intensity was found to be directly proportional to the grading of OSCC, where the poorly differentiated type had the highest staining intensity, followed by the moderately and the well differentiated grades, respectively.

IL-10 Tissue Expression in Correlation with the Histological Grading and Staging of OSCC

The difference in the mean IL-10 area percent and mean optical density between the well, moderately and poorly differentiated groups revealed statistical significance at $(\mathrm{P} \leq 0.05)$ (Tables 2 , $3)$. On the other hand, it was insignificant between OSCC stages $(\mathrm{P}>0.05)$.

Table 2: Relation between the Histological Grades and the Mean Area Percent.

\begin{tabular}{|c|c|c|c|}
\hline \multirow{2}{*}{} & \multicolumn{3}{|c|}{ Area Percent } \\
\cline { 2 - 4 } & Well & Moderate & Poor \\
\hline Min. & $28 \%$ & $27 \%$ & $60 \%$ \\
Max. & $42 \%$ & $55 \%$ & $62 \%$ \\
Mean & $34 \%$ & $43 \%$ & $61 \%$ \\
SD & 0.05 & 0.08 & 0.01 \\
\hline F (p) & \multicolumn{3}{|c|}{$10.73\left(<0.001^{*}\right)$} \\
\hline p1 & $<0.001^{*}$ \\
\hline p2 & \multicolumn{3}{|c|}{$<0.001^{*}$} \\
\hline p3 & $<0.001^{*}$ \\
\hline
\end{tabular}

F: F test (ANOVA)

$\mathrm{p}_{1}$ : $\mathrm{p}$ value for Post Hoc test for comparing between well and moderately differentiated cases

$\mathrm{p}_{2}$ : $\mathrm{p}$ value for Post Hoc test for comparing between well and poorly differentiated cases

$\mathrm{p}_{3}$ : $\mathrm{p}$ value for Post Hoc test for comparing between moderately and poorly differentiated cases

*: Statistically significant at $\mathrm{p} \leq 0.05$ 
Table 3: Relation between the Histological Grades and the Mean Optical Density.

\begin{tabular}{|c|c|c|c|}
\hline & \multicolumn{3}{|c|}{ Optical Density } \\
\cline { 2 - 4 } & Well & Moderate & Poor \\
\hline Min. & 80 & 101 & 130 \\
Max. & 92 & 109 & 135 \\
Mean & 85 & 104.1 & 132.5 \\
SD & 3.8 & 2.7 & 2.5 \\
\hline F (p) & \multicolumn{3}{|c|}{$170.1^{*}\left(<0.001^{*}\right)$} \\
\hline p1 & $<0.001^{*}$ \\
\hline p2 & \multicolumn{3}{|c|}{$<0.001^{*}$} \\
\hline p3 & $<0.001^{*}$ \\
\hline
\end{tabular}

F: F test (ANOVA)

$\mathrm{p}_{1}$ : $\mathrm{p}$ value for Post Hoc test for comparing between well and moderately differentiated cases

$\mathrm{p}_{2}$ : $\mathrm{p}$ value for Post Hoc test for comparing between well and poorly differentiated cases

$\mathrm{p}_{3}: \mathrm{p}$ value for Post Hoc test for comparing between Moderately and Poorly differentiated cases

*: Statistically significant at $\mathrm{p} \leq 0.05$

\section{ELISA Results}

Interleukin-10 levels in serum and saliva showed no significant difference between the study and the control groups $(\mathrm{P}>0.05)$.

IL-10 Tissue Expression in Correlation to Its Serum and Salivary Levels in OSCC Patients

Both mean area percent and mean optical density of IL-10 were significantly correlated to its serum and salivary levels $(\mathrm{P} \leq 0.05)$.

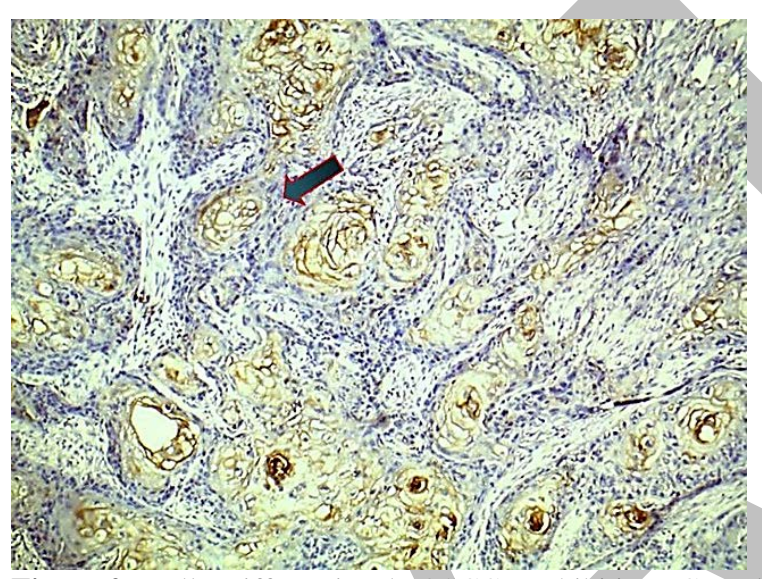

Figure 2: Well Differentiated OSCC Exhibiting Cytoplasmic Immunoreaction of IL-10 in the Central Malignant Epithelial Cells. The Peripheral Cells Are Devoid from Any Reaction (arrow) (Immuno stain of IL-10 x 100).

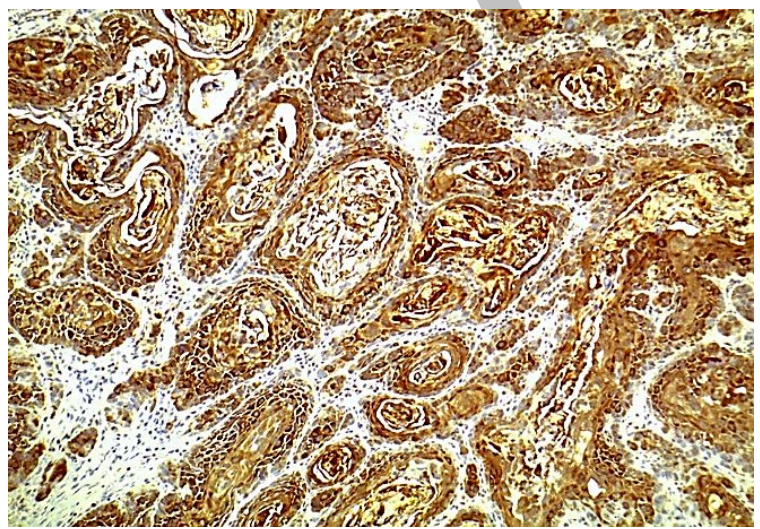

Figure 3: Moderately Differentiated OSCC Revealing Intense Immunopositive Reaction of IL-10 in the Malignant Cells Forming the Epithelial Cell Nests. (Immuno stain of IL-10 x100).



Figure 4: Moderately Differentiated OSCC Showing Evident Granular Cytoplasmic Immunoreactivity of IL-10 in the Malignant Epithelial cells. Notice that the Nuclei Are Free from any Immunoreaction (Immuno stain of IL-10 x 400).

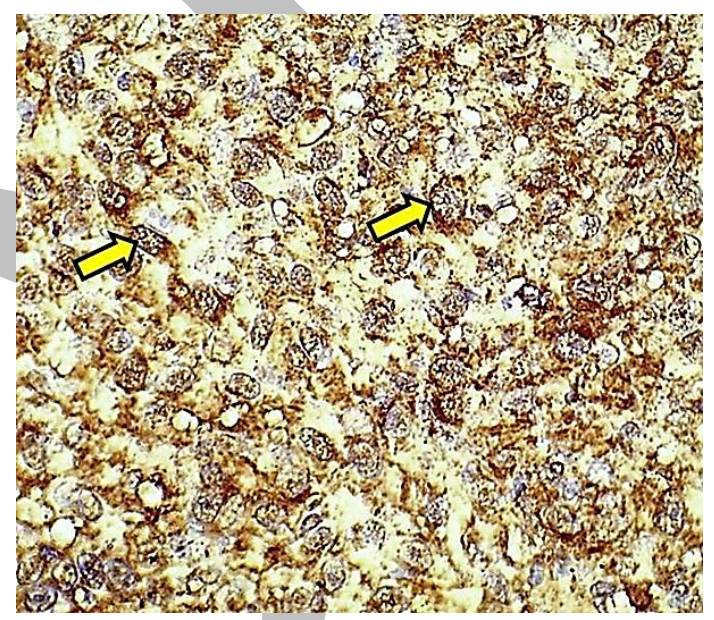

Figure 5: Poorly Differentiated OSCC Revealing Large Anaplastic Cells with Total Cell Reactivity to IL-10. Both the Cytoplasm and Nuclei of the Cells Show Granular Immunoreaction (arrows) (Immuno stain of IL-10 x 400).



Figure 6: Higher Magnification of the Previous Photomicrograph Showing Intense Granular Reaction of IL-10 in the Cytoplasm and Nuclei of the Malignant Epithelial Cells. Notice the Immunonegative Reaction of the Inflammatory Cells (arrows) (Immuno stain of IL-10 x 1000).

\section{DISCUSSION}

Interleukin-10 is an immunoregulatory cytokine with biological functions of anti-inflammation and immunosuppression. There is an evidence that this cytokine may play a role in cancer pathogenesis (11). Multiple studies detected high levels of IL-10 produced by the tumor cells in different types of malignancy. Sakamoto et al (8) reported IL-10 production by gastric cancer cells 
and correlated this finding with reduced patients survival. In addition, Immunohistochemistry revealed that IL-10 is localized in the tumor cells of primary breast adenocarcinomas in the study conducted by Heckel et al (9). Furthermore, IL-10 expression was confirmed within the cells of non-small-cell lung cancer (10), melanomas (12) and lymphomas (13).

The present study revealed that IL-10 was expressed in all OSCC samples, while it was absent in the normal mucosal tissues. These results were consistent with the studies conducted by Fujieda et al (14) and Hamzavi et al (7). In their work, the incidence of IL-10 was observed in $82 \%$ and $86.6 \%$ respectively of the tumor tissue samples. However, Chandler et al (15) found that 65\% of OSCC tissues showed expression of IL-10. This lower occurrence of IL-10 may be due to problems in the process of antigen retrieval or differences in the tendency of primary antibody in binding to antigen.

In this study, a cytoplasmic expression of IL-10 was revealed in the malignant epithelial cells. This conforms to the data collected by most of the researchers $(7,11,15-18)$. Interestingly, both cytoplasmic and nuclear immunoreactions were observed in the poorly differentiated as found in the present research.

The inflammatory cells within the tumor stroma showed negative IL-10 immunoreaction. This was in accordance with the study conducted by Chandler et al (15). They observed the localization of IL-10 in the cancer cells only. Similar results were found by Smith et al (19). Consequently, it is assumed that IL-10 could be primarily tumor-derived rather than being a product of the immune cells. On the other hand, many authors detected IL-10 expression in the inflammatory cells which are distributed over the tumor stroma $(7,11,16-18)$.

The present study revealed that IL-10 expression was significantly correlated with the tumor grade. The poorly differentiated grade is associated with the highest expression, followed by the moderately and well differentiated types respectively. Contradictory results were found by Chandler et al (15). They mentioned that IL-10 expression was inversely related to the grade. On the other hand, Chen et al (11) found that no significant association was found between IL-10 expression and the tumor grade. The discrepancy between the present data and the previous reports may be due to the limited sample size with few cases of the poorly differentiated grade.

In the current work, the expression of IL-10 had no association with the clinical staging of OSCC. This is in agreement with Fujieda et al (14) and Wang et al (16). On the other hand, Hamzavi et al (7) stated that a significant correlation was found between IL-10 and the disease stage; such that the incidence of IL-10 decreases in higher stages. This discrepancy could be due to the mixed sample from different head and neck locations in the previously mentioned study. Conversely, high IL-10 expression was associated with advanced clinical stages in the study conducted by Arantes et al (18). This diversity of the results may be explained as, $68 \%$ of the patients studied by those authors had an advanced stage of OSCC, in comparison to only $25 \%$ of the cases encountered in the present work.

According to the present research, IL-10 was detected in the serum of OSCC patients. However, the detectable IL10 concentrations showed no significant difference between patients and controls. This goes with the results of
Hamzavi et al (7), Alhamarneh et al (20) and Czerninski et al (21). Moreover, in the study conducted by Linkov et al (22) there was no difference between IL-10 serum level of patients with HNSCC and that of the control group who were smokers.

In contradiction to the current research results, Interleukin-10 was not detected in the serum of patients with SCC and adenoid cystic carcinoma of the head and neck in the study conducted by Hoffmann et al (23). Conversely, De Vita et al (24) detected elevated levels of serum IL-10 in gasterointestinal carcinoma patients compared with healthy controls. Similar results were reported in patients with different types of solid and hematopoietic tumors (25-28), suggesting that serum IL-10 overproduction may be a shared observation in certain types of human malignancies.

It is observed that high IL-10 serum levels were detected in the advanced stages of malignancy (24). Unfortunately, the number of patients who were in the advanced disease stages (stage III and IV) was low in the present study. This could be a possible explanation for the decreased IL-10 serum levels. Another reason for the contradictory results is related to the difference in the methods of measuring IL-10 in serum (25). In addition, having radiotherapy or chemotherapy before giving blood samples could be also a cause for this discrepancy (26). In the current work, the salivary levels of IL-10 in OSCC patients were slightly higher than in the healthy individuals. However, the difference between the two groups was not statistically significant. Similar results were found by Hamzavi et al (7). Furthermore, In a study conducted by Nelson et al (29) on cervical cancer, salivary IL-10 level was evaluated. It showed no significant difference between patients and controls. These results may assume that the presence of IL-10 in the saliva is most likely to exert a physiological role and it might not constitute a significant salivary biomarker for OSCC (17).

Contrary to the current results, Aziz et al (30) and Arantes et al (18) found that the mean salivary concentrations of IL-10 in OSCC individuals were significantly higher than their healthy counterparts. Additionally, Goncalves et al (17) detected elevated levels of this cytokine in the saliva of patients with OSCC. This finding enabled the authors to distinguish patients with cancer from healthy individuals. These studies concluded that IL-10 has a great potential for becoming a salivary biomarker for OSCC.

Furthermore, Polz-Dacewicz et al (31) stated that the level of IL-10 in serum and saliva was higher in oropharyngeal SCC patients than in controls. The authors added that the concentration of IL-10 in the patients group was higher in saliva than in serum.

The conflicting data regarding the salivary expression of IL10 may be due to the fundamental differences in the composition of saliva in cancer patients (30). Furthermore, the different sites of the cancerous lesions in the mentioned studies could be a cause of contradiction. In oral cavity carcinomas, the neoplastic cells are closely associated with the salivary fluid. This is distinct from other locations such as the larynx and pharynx (17). Moreover, oral environmental factors, including periodontal disease and oral microbial flora, can lead to detection of protein artifacts, making a difficult comparison between individuals on basis of salivary composition. Additionally, it is interesting to notice that serum and salivary IL-10 levels increase in response to acute stress as mentioned 
by Szabo et al (32), so that the psychosocial factors might affect the current results. Finally, Wozinak et al (33) found that salivary cytokines may be degraded by enzymes or mucin-like proteins which are found in the saliva.

Finally, a significant correlation was found among IL-10 tissue expression and its serum and salivary levels in OSCC patients. This could reflect the same way of regulation of this cytokine in different parts of the body. Conversely, Hamzavi et al (7) concluded that no significant correlation was found between IL-10 concentrations in tissue, serum and saliva.

\section{CONCLUSIONS}

Interleukin-10 can be detected immunohistochemically in OSCC biopsies. The intensity of its expression is directly proportional to the histopathological grading of the disease. Moreover, the levels of IL-10 in tissue, serum and saliva are correlated with each other. This could reflect the same way of regulation of this cytokine in different parts of the body.

\section{CONFLICT OF INTEREST}

The authors declare that they have no conflicts of interest.

\section{REFERENCES}

1. Sharma P, Saxena S, Aggarwal P. Trends in the epidemiology of oral squamous cell carcinoma in Western UP: an institutional study. Indian J Dent Res. 2010; 21:3169.

2. Singh PK, Ahmad MK, Kumar V, Gupta R, Kohli M, Jain A, et al. Genetic polymorphism of interleukin-10 (-A592C) among oral cancer with squamous cell carcinoma. Arch Oral Biol. 2017; 7:56-70.

3. de Castro Junior G, dos Santos-Silva AR, Folgueira MAdAK, Toporcov T. Tongue cancer in the young. Curr Opin Oncol. 2016; 28:193-4.

4. Karin M. Nuclear factor ${ }_{k} B$ in cancer development and progression. Nature. 2006; 441:431-6.

5. Aivaliotis IL, Pateras IS, Papaioannou M, Glytsou C, Kontzoglou K, Johnson EO, et al. How do cytokines trigger genomic instability? J Biomed Biotechnol. 2012; 14:1681-5.

6. Dranoff G. Cytokines in cancer pathogenesis and cancer therapy. Nat Rev Cancer. 2004; 4:11-22.

7. Hamzavi M, Tadbir AA, Rezvani G, Ashraf MJ, Fattahi MJ, Khademi B, et al. Tissue expression, serum and salivary levels of IL-10 in patients with head and neck squamous cell carcinoma. Asian Pac J Cancer Prev. 2013; 14:1681-5.

8. Sakamoto T, Saito H, Tatebe S, Tsujitani S, Ozaki M, Ito H, et al. Interleukin-10 expression significantly correlates with minor CD8+ T cell infiltration and high microvessel density in patients with gastric cancer. Int J Cancer. 2006; 118:1909-14.

9. Heckel MC, Wolfson A, Slachta CA, Schwarting R, Salgame P, Katsetos CD, et al. Human breast tumor cells express IL-10 and IL-12p40 transcripts and proteins, but do not produce IL-12p70. Cell Immunol. 2011; 266:143-53.

10. Hatanaka H, Abe Y, Kamiya T, Morino F, Nagata J, Tokunaga $\mathrm{T}$, et al. Clinical implications of interleukin (IL)10 induced by non-small-cell lung cancer. Ann Oncol. 2000; 11:815-9.

11. Chen CJ, Sung WW, Su TC, Chen MK, Wu PR, Yeh KT, et al. High expression of interleukin 10 might predict poor prognosis in early stage oral squamous cell carcinoma patients. Clin Chim Acta. 2013; 415:25-30.

12. Itakura E, Huang RR, Wen DR, Paul E, Wunsch PH, Cochran AJ. IL-10 expression by primary tumor cells correlates with melanoma progression from radial to vertical growth phase and development of metastatic competence. Mod Pathol. 2011; 24:801-9.

13. Boulland ML1, Meignin V, Leroy-Viard K, CopieBergman C, Brière J, Touitou R, et al. Human interleukin10 expression in T/natural killer-cell lymphomas: association with anaplastic large cell lymphomas and nasal natural killer-cell lymphomas. The Am J Pathol. 1998; 153:1229-37.

14. Fujieda S, Sunaga H, Tsuzuki H, Fan GK, Saito H. IL-10 expression is associated with the expression of plateletderived endothelial cell growth factor and prognosis in oral and oropharyngeal carcinoma. Cancer Lett. 1999; 136:1-9.

15. Chandler SW, Rassekh CH, Rodman SM, Ducatman BS. Immunohistochemical Localization of Interleukin-10 in Human Oral and Pharyngeal Carcinomas. Laryngoscope. 2002; 112:808-15.

16. Wang S, Sun M, Gu C, Wang X, Chen D, Zhao E, et al. Expression of CD163, interleukin-10, and interferon gamma in oral squamous cell carcinoma: mutual relationships and prognostic implications. Eur J Oral Sci. 2014; 122:202-9.

17. Gonalves AS, Arantes DAC, Bernardes VF, Jaeger F, Silva JM, Silva TA, et al. Immunosuppressive mediators of oral squamous cell carcinoma in tumour samples and saliva. Hum Immunol. 2015; 76:52-8.

18. Arantes DAC. Overexpression of immunosuppressive cytokines is associated with poorer clinical stage of oral squamous cell carcinoma. Arch Oral Biol. 2015; 5:1077-89.

19. Smith DR, Kunkel SL, Burdick MD, Wilke CA, Orringer MB, Whyte RI, et al. Production of interleukin-10 by human bronchogenic carcinoma. Am J Pathol. 1994; 145:18-25.

20. Alhamarneh O, Agada F, Madden L, Stafford N, Greenman J. Serum IL10 and circulating CD4+ CD25high regulatory T cell numbers as predictors of clinical outcome and survival in patients with head and neck squamous cell carcinoma. Head Neck. 2010; 33:415-23.

21. Czerninski R, Basile JR, Kartin Gabay T, Laviv A, Barak $\mathrm{V}$. Cytokines and tumor markers in potentially malignant disorders and oral squamous cell carcinoma: a pilot study. Oral Dis. 2014; 20:477-81.

22. Linkov F, Lisovich A, Yurkovetsky Z, Marrangoni A, Velikokhatnaya L, Nolen B, et al. Early detection of head and neck cancer: development of a novel screening tool using multiplexed immunobead-based biomarker profiling. Cancer Epidemiol Biomarkers Prev. 2007; 16:102-7.

23. Hoffmann TK, Sonkoly E, Homey B, Scheckenbach K, Gwosdz C, Bas M, et al. Aberrant cytokine expression in serum of patients with adenoid cystic carcinoma and squamous cell carcinoma of the head and neck. Head Neck. 2007; 29:472-8.

24. De Vita F, Orditura M, Galizia G, Romano C, Infusino S, Auriemma A, et al. Serum interleukin-10 levels in patients with advanced gastrointestinal malignancies. Cancer. 1999; 86:1936-43.

25. Avradopoulos K, Mehta S, Blackinton D, Wanebo HJ. Interleukin-10 as a possible mediator of immunosuppressive effect in patients with squamous cell carcinoma of the head and neck. Ann Surg Oncol. 1997; 4:184-90.

26. Fortis C, Foppoli M, Gianotti L, Galli L, Citterio G, Consogno $\mathrm{G}$, et al. Increased interleukin-10 serum levels in patients with solid tumours. Cancer Lett. 1996; 104:1-5. 
27. Gianotti L, Fortis C, Braga M, Gentilini O, Vignali A, Di Carlo V. Radical oncologic surgery affects the circulatory levels of interleukin 10. J Surg Oncol. 1997; 66:244-7.

28. Gaiolla RD, Domingues MAC, Niero-Melo L, de Oliveira DE. Serum levels of interleukins 6, 10, and 13 before and after treatment of classic Hodgkin lymphoma. Arch Pathol Lab Med. 2011; 135:483-9.

29. Nelson EL, Wenzel LB, Osann K, Dogan-Ates A, Chantana $\mathrm{N}$, Reina-Patton A, et al. Stress, immunity, and cervical cancer: biobehavioral outcomes of a randomized clinical trial. Clin Cancer Res. 2008; 14:2111-8.

30. Aziz S, Ahmed SS, Ali A, Khan FA, Zulfiqar G, Iqbal J, et al. Salivary immunosuppressive cytokines IL-10 and IL-13 are significantly elevated in oral squamous cell carcinoma patients. Cancer Invest. 2015; 33:318-28.

31. Polz-Dacewicz M, Strycharz-Dudziak M, Dworzaski J, Stec A, Kocot J. Salivary and serum IL-10, TNF- $\alpha$, TGF- $\beta$, VEGF levels in oropharyngeal squamous cell carcinoma and correlation with HPV and EBV infections. Infect Agent Cancer. 2016; 11:45.

32. Szabo YZ, Newton TL, Miller JJ, Lyle KB, FernandezBotran R. Acute stress induces increases in salivary IL-10 levels. Stress. 2016; 19:499-505.

33. Wozniak KL, Arribas A, Leigh JE, Fidel PL. Inhibitory effects of whole and parotid saliva on immunomodulators. Oral Microbiol Immunol. 2002; 17:100-7. 